\title{
EVALUATION OF THE EFFECT OF SOCIAL MEDIA IN DENTISTRY
}

\author{
Dr. Durga Bhattad ${ }^{3}$, Dr Suryakant Kumar ${ }^{1}$, Dr. Milind Wasnik ${ }^{2}$, Dr. Niharika Gahlod ${ }^{2}$, Dr. Harshita Shukla ${ }^{3}$, \\ Dr. Nilesh P.Rojekar ${ }^{3}$
}

1- Reader, 2-Senior Lecturer, 3- Postgraduate Student, Department of Pedodontics and Preventive Dentistry, Swargiya Dadasaheb Kalmegh Smruti Dental College and Hospital, Nagpur

\section{ABSTRACT}

A large part of day to day interaction takes place through social media. Social media is the way people communicate, look for and share information among all age groups. Social media has begun to proliferate across the fields of medicine and dentistry also. The use of social media seems to transform the way of interaction between the dentist and the patient and open up new avenues of communication. Aim: To evaluate the willingness to use the social media among patients, dentists, and their networks to advocate and educate about oral health care. To explore patients' and dentists' attitude towards social media usage in dentistry and to discover potential opportunities and challenges for dentists to adopt social media practices. Material and method: A cross-sectional study, Sampling technique: Stratified Random Sample size: 115 dentists, 115 patients. A close ended questionnaire was prepared and distributed among 115 dentist and 115 patients consisting of 10 sets of questions each for dentist and parents. Result: In this study, it was found that $55.38 \%$ of dentists were willing to use social media and their network to educate about oral health care and $39.12 \%$ parents were willing to use social media for the same. Conclusion: Pedodontists actively use social media to educate about oral health care while use of social media among parents is less.

KEY WORDS: Dentist, oral health, social media.

\section{INTRODUCTION}

Social media are the tools which support electronic conversation. According to Scott and Jacka "There is no single recognized definition of social media". According to Kaplan and Haenlein, social media are "a group of internet based applications which is build on the ideological and technological foundations of Web 2.0. ${ }^{2}$

Social media is an inexpensive, powerful, and significant way of using Internet-based tools.

Social media is used to facilitate easy and broad communication and also it is used for sharing of information and opinions. ${ }^{1,2}$ The usage of social media is good medium of communication. The health providers need to understand and adapt to social media and its use as a potential method of interacting with patients to provide health care. ${ }^{1-3}$ The use of social media in health care education has mainly been an area of increasing interest as a means of better engaging and enhancing the learning of students. A number of studies have been conducted to investigate the ways in which the health care students informally use social media for educational purposes. ${ }^{4}$

Social media in dentistry has been used in training and development of dental professionals. ${ }^{7}$ Dental 
education relies on online communication to help dental professionals to develop clinical skills. ${ }^{8}$ Previous studies have also highlighted that social media assists dentists to share area of knowledge with each other and aid professional networks. ${ }^{9}$ It also allows the professionals from different locations to connect with one another and to discuss important issues and obtain also to obtain feedback. These activities benefit lifelong learning and professional development. ${ }^{10}$

Dental professionals can use social media as an effective and comparatively inexpensive means of communication, for marketing activities ${ }^{11}$. Traditionally, dental practices would use to primarily advertise their services using local yellow pages (i.e, telephone directory of local businesses and services) or else they would put the promotion information on a small note in the window of dental surgeries. In the modern years of digital transformation, social media has offered a forum for public communication that dentists can influence to conduct marketing activities and to in a timely and cost-efficient way. ${ }^{12,13}$

Hence, this study aimed to assess to evaluate the willingness to use of the social media among Patients and Dentists.

\section{AIM}

- To evaluate the willingness to use of the social media among Patients and Dentists.

\section{MATERIALS AND METHODS}

Study design: A cross-sectional study

Sampling Technique: Stratified Random Sampling Method

\section{Sample size}

- 115 Dentists

- 115 Patients

A close ended questionnaire was prepared and distributed among 115 dentist and 115 patients consisting of 10 sets of questions each for dentist and parents.

\section{RESULTS}

A cross-sectional study was conducted among 230 participants where 115 were Dentists and 115 were Patients. A questionnaire was prepared consisting of 10 sets of questions each for dentist and parents. During Survey among Dentist, $67.82 \%$ were willing to share information regarding prevention of dental caries and treatment through use of social media while $32.17 \%$ were not.(Table no. 1) Similarly 73.04\%Dentists think that social media will help you their better establishment while $26.95 \%$ disagreed with this fact. (Table no. 1) On enquiring that weather use of social media helps in making parents better understand the various aspect of dental treatment, $78.04 \%$ dentist were in favor of it while $21.73 \%$ were not. (Table no. 1) During Survey among Patients $54.78 \%$ believe that social media is helpful for dental information while $45.21 \%$ did not think so. (Table no. 2) Similarly $49.56 \%$ think that social media is easy way to approach the dentist while $50.43 \%$ were not in favour of it. (Table no. 2)

In this study it was found that $55.38 \%$ of Dentists were willing to use social media and their network to educate about oral health care and $39.12 \%$ parents were willing to use social media for the same. (Graph 1)

\section{DISCUSSION}

Several studies discussed about the professionalization of the use of social media by the dentist, along with the effectiveness of communication, education of patients, their perceptions and attitudes as well as studies concerning treatment experiences, ethical skills, and standards of professional practice. Numerous studies explored the different ways in which social media networks can help the dentist but also hamper the practice of the dentist. Some studies explored the perspectives on the management of dental fear and anxiety particularly in pediatric patients. ${ }^{14-21}$ Several dental practitioners have their own practice websites and Facebook pages. 


\section{Table no. 1:- Questions for Dentist}

\begin{tabular}{|c|c|c|}
\hline & YES & NO \\
\hline 1) Do you have a personal social media account? & $88.69 \%$ & $11.30 \%$ \\
\hline $\begin{array}{l}\text { 2) Would you be willing to share information regarding } \\
\text { prevention of dental caries and treatment? }\end{array}$ & $67.82 \%$ & $32.17 \%$ \\
\hline $\begin{array}{l}\text { 3) Would you like to share video regarding various dental } \\
\text { treatment aspect? }\end{array}$ & $46.95 \%$ & $53.04 \%$ \\
\hline 4) Have you ever posted video of treatment carried by you? & $6.08 \%$ & $93.91 \%$ \\
\hline $\begin{array}{l}\text { 5) Do you think the social media will help you for better } \\
\text { establishment? }\end{array}$ & $73.04 \%$ & $26.95 \%$ \\
\hline $\begin{array}{l}\text { 6) Would you like to use social media for making parents } \\
\text { better understanding of various aspect of dental } \\
\text { treatment? }\end{array}$ & $78.04 \%$ & $21.73 \%$ \\
\hline $\begin{array}{l}\text { 7) Does social media will be able to build trust and } \\
\text { confidence between dentist and parents? }\end{array}$ & $46.95 \%$ & $53.04 \%$ \\
\hline $\begin{array}{l}\text { 8) Does posting video and sharing information will help to } \\
\text { showcase your leadership? }\end{array}$ & $46.95 \%$ & $53.04 \%$ \\
\hline $\begin{array}{l}\text { 9) Do you think social media is easy and best way to } \\
\text { interact with parents? }\end{array}$ & $36.52 \%$ & $63.47 \%$ \\
\hline $\begin{array}{l}\text { 10) Do you think social media is beneficial for promotion of } \\
\text { clinic? }\end{array}$ & $62.60 \%$ & $37.39 \%$ \\
\hline
\end{tabular}

\section{Table no.2:- Questions for Parents}

\begin{tabular}{|l|c|c|}
\hline & YES & NO \\
\hline 1) Do you use social networking site on the internet? & $72.17 \%$ & $27.82 \%$ \\
\hline 2) Do you have a personal social media account? & $67 \%$ & $33 \%$ \\
\hline 3) Do you ever visit any Dentist's social media account? & $20 \%$ & $80 \%$ \\
\hline 4) Do you ever visit on social media before going to dentist? & $37.39 \%$ & $62.60 \%$ \\
\hline 5) Do you believe social media is helpful? & $54.78 \%$ & $45.21 \%$ \\
\hline 6) Do you think social gives platform that will help you to \\
communicate with dentist?
\end{tabular}


They post their practice opening hours, updates on health topics and often, testimonials from satisfied patients. $^{24}$

There is inadequate use of social media as a means to facilitate communication between dentists and their patients. ${ }^{7}$ The current findings showcase that both dentists and patients remain somewhat hesitant to connect with each other as friends on social media. ${ }^{7,22}$ The most common source of media is Facebook which is typically used to connect with friends and family ${ }^{23}$. The findings of the present study highlight that dentists value social media as useful marketing tool (73\%). On the contrary, as the target audience, most patients do not consider social media as part of their decision-making process (20\%). Similarly $46.95 \%$ Dentist believed that social media will be able to build trust and confidence between dentist and parents. About $49.56 \%$ parents think that social media is easy way to approach the dentist.

Presently there is a degree of importance about raising awareness of the risks and benefits of social media for professional practice. All dental practitioner, before they tweet or post a comment or photo in any context, should know to pause and reflect. The Dentist should be enabled to refuse permission when an inappropriate content or comment to be posted on photograph. Very little research has been conducted on how best to teach or increase awareness of e-professionalism. ${ }^{26}$ One email survey of 221 educators which was conducted across five different dental schools in the US found that the majority of university faculty used social media for personal use and not educational purposes and so it might not necessarily act as positive role models of professional online communications. ${ }^{17,27}$

\section{CONCLUSION}

Social media are very popular among the study participants. (Dentist and Parents). Social media will continue to develop proper social and professional interactions between practitioners and the public in the years to come.

\section{REFERENCES}

1.Scott, PR., Jacka JM. Eds. 2012. Front Matter. In Auditing social media: a governance and risk guide. Hoboken, NJ, USA: John Wiley \& Sons, Inc.

2.Kaplan AM, Haenlein M. 2012. Users of the world, unite! The challenges and opportunities of social media. Bus Horiz. 53:59-68.

3.Van De Belt TH, Engelen LJ, Berben SA, Schoonhoven L. Definition of health 2.0 and medicine 2.0: a systematic review. J Med Internet Res 2010 Jun 11;12(2):e18

4.Chretien KC, Kind T. Social media and clinical care: ethical, professional, and social implications. Circulation 2013 Apr 2;127(13):1413-1421.

5. Maloney S, Moss A, Ilic D. Social media in health professional education: a student perspective on user levels and prospective applications. Adv Health SciEduc Theory Pract 2014 Dec;19(5):687697.

6.Cheston CC, Flickinger TE, Chisolm MS. Social media use in medical education: a systematic review. Acad Med 2013 Jun;88(6):893-901.

7.Neville P, Waylen A. Social media and dentistry: Some reflections on e-professionalism. Br Dent $\mathrm{J}$ 2015 Apr 24;218(8):475-478.

8.GOV.UK. Digital strategy: Leading the culture change in health and care.

9.Sugawara Y, Narimatsu H, Tsuya A, Tanaka A, Fukao A. Medical institutions and twitter: A novel tool for public communication in Japan. JMIR Public Health Surveill 2016;2(1):e19. 
10.Keller B, Labrique A, Jain KM, Pekosz A, Levine O. Mind the gap: Social Media engagement by public health researchers. J Med Internet Res 2014;16(1):e8

11.Shibasaki S, Gardner K, Sibthorpe B. Using knowledge translation to craft "sticky" Social Media health messages that provoke interest, raise awareness, impart knowledge, and inspire changes. JMIR M health U health 2016;4(4):e115.

12.Melkers J, Hicks D, Rosenblum S, Isett KR, Elliott J. Dental blogs, podcasts, and associated social media: Descriptive mapping and analysis. J Med Internet Res 2017 Jul 26;19(7):e269.

13.Gao X, Hamzah SH, Yiu CKY, McGrath C, King NM. Dental fear and anxiety in children and adolescents: Qualitative study using YouTube. J Med Internet Res 2013;15(2):e29.

14.Glaizel J. Plugged in: social media in the dental profession. J Can Dent Assoc 2013 ;79:d148.

15.Song M, O’onnell JA, Bekhuis T, Spallek H. Are dentists interested in the oral-systemic disease connection? A qualitative study of an online community of 450 practitioners. BMC Oral Health. 2013;13:65.

16.Hamzah HS, Gao X, Yung Yiu CK, McGrath C, King NM. Managing dental fear and anxiety in pediatric patients: A qualitative study from the public's perspective. Pediatr Dent. 2014 JanFeb;36(1):29-33.

17.Neville P, Waylen A. Social media and dentistry: some reflections on e-professionalism. $\mathrm{Br}$ Dent J. 2015 Apr 24;218(8):475-8.

18.Parsons CF, Breckons M, Durham J. Twitter: a viable medium for daily pain diaries in chronic orofacial pain? Br Dent J. 2015;219(2):75-8.
SJ. Effect of social media in improving knowledge among patients having fixed appliance orthodontic treatment: A single-center randomized controlled trial. Am J Orthod Dentofacial Orthop. 2015 Aug;148(2):231-7.

20.Migliorati M. Effective communication in dentistry in the new media era. Dental Cadmos. 2016;84(1):16-29.

21. Seymour B, Yang H, Getman R, Barrow J, Kalenderian E. Patientcentered communication: exploring the dentist's role in the era of e-patients and health 2.0. J Dent Educ. 2016 Jun;80(6):697704.

22. Gholami-Kordkheili F, Wild V, Strech D. The impact of social media on medical professionalism: A systematic qualitative review of challenges and opportunities. J Med Internet Res 2013;15(8):e184.

23. Eisingerich AB, Chun H, Liu Y, Jia HM, Bell SJ. Why recommend a brand face-to-face but not on Facebook? How word-of-mouth on online social sites differs from traditional word-of-mouth. Journal of Consumer Psychology 2015;25(1):120128.

24. Eckler P, Worsowicz G, Wesley Rayburn J. Social media and health care: an overview. $P M R$ 2010; 2: 1046-1050.

25.Thompson C A, Black E, Duff W P. Protected health information on social networking sites: ethical and legal considerations. J Med Internet Research 2011;13: e8.

26.Kumar K. Views of medical e-professionalism: a comparison, Clin Teach 2014; 11: 70-73.

27.Arnett M R, Loewen J M, Romito LM. Use of social media by dental educators. J Dent Ed 2013; 7: 1402-1412. 